\title{
The Effect of Additives on Denture Base Resin Properties
}

\author{
Wafaa A. Hussain and Furqan Salim Hashim \\ Department of Applied Sciences, University of Technology, Baghdad-Iraq. \\ Corresponding Author: shademan747@gmail.com.
}

\begin{abstract}
Numerous studies have been carried out on studying the effect of glass fiber and $\mathrm{ZrO}_{2}$ Nanoparticles alone on the mechanical properties of PMMA, to date, no investigations were made that have studied the mechanical properties of PMMA reinforced with glass fiber and zirconium oxide together as a hybrid composite.

In this research the effect of addition of glass fibers (woven and chopped) and Zirconium oxide Nano-particles $\left(\mathrm{ZrO}_{2}\right)$ with different weight percent to the conventional poly (methyl methacrylate) (PMMA) has been evaluated.

The conventional acrylic resin was used as 2:1 powder to liquid ratio to prepare pure sample, laminate composite prepared by using woven glass fiber $(8 \mathrm{wt} \%, 12 \mathrm{wt} \%)$, fiber-reinforced composite fabricated by chopped glass fiber $(8 \mathrm{wt} \%, 12 \mathrm{wt} \%)$, particle-reinforced composite prepared by using $\mathrm{ZrO}_{2}$ Nano-powder $(1,2,3) \mathrm{wt} \%$, and the hybrid composite fabricated by using glass fiber as woven or chopped of the two form with $\mathrm{ZrO}_{2}$ Nano-particles.

The flexural strength (F.S.) was measured by using three point-bending test. The mechanical test done in order to compare the flexural strength between pure and composite samples. The form of glass fiber with the same weight percent affects the mechanical properties values. Reinforcing PMMA with woven glass fiber and zirconium oxide increase flexural strength, while incorporation of chopped glass fiber decrease the flexural strength. Using the two materials together as a hybrid composite recorded very high raises of flexural strength values. From the results, it's possible to syntheses a denture base resin with good aesthetic and high mechanical properties from fiber and $\mathrm{ZrO}_{2}$ Nano-particles. [DOI: $\left.10.22401 / J N U S .20 .4 .08\right]$
\end{abstract}

Keywords: Denture base, glass fiber, $\mathrm{ZrO}_{2}$ Nano-powder.

\section{Introduction}

History of complete denture (which is a tool that has been manufactured to replace lost teeth and be supported by strong and soft tissues surrounding it) back to $700 \mathrm{BC}$, however; complete dentures are constructed from several materials for instance; wood, bone, rubber, and ivory. The polymers such as cellulose plastics, poly (vinyl chloride), and vinyl acetate became used since 1900's. However, the Poly (methyl methacrylate) [PMMA] material used as denture base material for the first time in 1937 by Walter Wright. From that time this material became the most excellent material as denture base material and it's became so prevalent in 1940s' $[1,2]$.

The PMMA has many characteristics made it used as denture material such as; ease in processing, stability in the oral environment, lightweight, excellent aesthetic properties, low cost, low water absorption, and can easily re- change and repaired its shape [1,2]. However, the PMMA has some problems such as; brittleness, low modulus of elasticity, low impact strength, and low flexural strength [3].

Many materials are used to reinforce the denture such as; metal in the form of wires, plate's, or powder but it has poor aesthetic and poor adhesion between metal and acrylic resin matrix. While the rubber toughening agents have been used as strengthen material but its expensive [3].

Ceramic nano-particles powders have been used to reinforce the PMMA as a biocompatible and good aesthetic materials but no significant difference was detected in impact strength. [4,5].

There are many types of fibers that can be used as reinforcement for denture base resins such as; polyethylene fibers, aramid fibers, and carbon fibers, but the carbon adversely effects on denture aesthetic because it's black color, while the Kevlar fibers are also used to 
reinforce and strength the PMMA; but they are causing problems in esthetics and difficult in polishing $[3,6]$.

Glass fibers are used to enhance the mechanical properties of denture base polymers such as the ultimate tensile strength, transverse strength, and impact strength, it have easy manipulation, and they are esthetic [6].

M. Vojdani1, et.al [3] and IH Tacir, et.al [7] studied the effect of glass fiber on transverse strength of denture base resin. The flexural strength was enhanced by reinforcing with glass fibers.

The aim of this work is to investigate flexural strength of PMMA resin, and studding the effect of glass fiber (woven and chopped) and $\mathrm{ZrO}_{2}$ nanoparticles addition alone and together on flexural strength.

\section{Materials and Methods \\ Woven with $(65 \times 65) \mathrm{mm}^{2}$, chopped $(5 \mathrm{~mm})$ length glass fiber (Tian tan A District, Huling Industry Zone, Jiyuan city, Henan ,China), and prepared zirconium oxide $\left(\mathrm{ZrO}_{2}\right)$ Nano- particle powder were used to reinforce the denture base material.}

\section{Denture base material}

The materials used for denture base are heat cured acrylic resin poly (methylemethacrylet), monomer methylmethacrylet (PMMA, MMA, New Stetic, Veracril ${ }^{\circledR}$, Colombia). The mold materials are made from Stone (Zhermack $^{\circledR}$ Technical, eite ${ }^{\circledR}$ stone, NAVY BLUE, Italy) and kaolin.

\section{Preparation of the mold (flask)}

Denture base fabricated by specially designed flask. The flask have two parts, one half of the flask filled with freshly dental stone, while the other half invested with square kaolin $(65 \times 65 \times 3) \mathrm{mm}^{3}$ and poured the stone to fill the flask. The flask was shacked to remove bubbles from the stone. The inner surface of each flask half were coated with Vaseline to prevent the investment material from attaching to the cast. The flask left to dry at room temperature for 2 hours, and then follow opened and cleaned form kaolin as shown in Fig.(1).

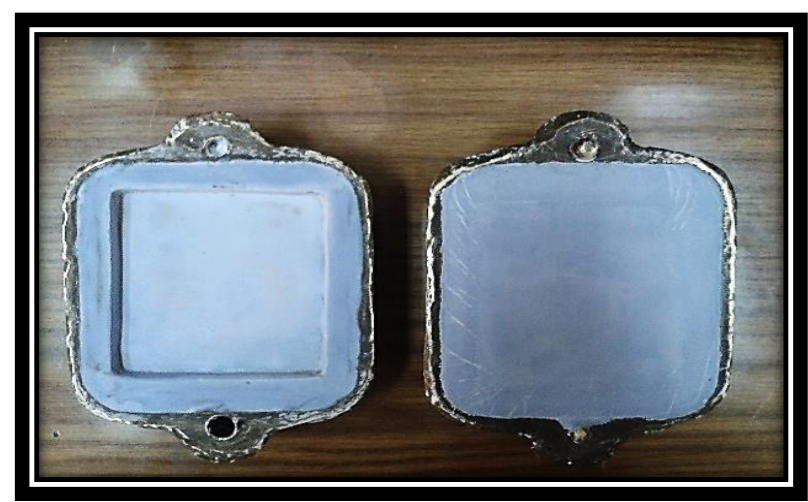

Fig.(1): Flask of samples.

\section{Treatment of fiber (Salinization):}

To improve the adhesion between glass fiber and acrylic resin matrix, a silane coupling agent used to wet the fiber before loading into the acrylic resin matrix. A (0.3) g silane coupling agent were added to $100 \mathrm{ml}$ of water and alcohol solution (50 $\mathrm{ml}$ for each of them). The fiber immersed into the silane mixture for $10 \mathrm{~min}$, and then dried at $100^{\circ} \mathrm{C}$ for 1 hour. [6]

\section{Experimental}

The 14 experimental groups of denture base were prepared as shown in Table (1). The specimens were fabricated by conventional heat-polymerized acrylic resin, the powder to liquid ratio is $2: 1$ by weight mixed and left for 10 minutes until reach the dough stage and then kneaded to remove the voids. In Group (A) (Pure PMMA) the dough was placed directly in the mold. In the Groups which contain woven GF the dough was cut into two halves, and the woven glass fiber placed between them, while the Groups with chopped GF or $\mathrm{ZrO}_{2}$ Nano-powder the reinforcement materials were mixed with polymer powder. The mold pressed by hydraulic press at 1 Ton for 3 minutes. The flask immersed in water bath at room temperature and heated to $100^{\circ} \mathrm{C}$ then left at boiling temperature for 1 hour to complete the polymerization process and then cooled at room temperature. The specimens extracted from the mold as shown in Fig.(2), then cut to specific dimension $(65 \times 10 \times 3)$ to all tests and polished with 350,400 , and 800 -grit Sic paper. 
Table (1)

Classification of test specimens according to type of reinforcement.

\begin{tabular}{|c||c||c||c||}
\hline Groups & PMMA & $\begin{array}{c}\text { Glass Fiber } \\
\text { wt. \% }\end{array}$ & $\begin{array}{c}\text { ZrO }_{2} \\
\text { wt.\% }\end{array}$ \\
\hline \hline 1 & 100 & 0 & 0 \\
\hline \hline 2 & 92 & Woven (8) & 0 \\
\hline \hline 3 & 88 & Woven (12) & 0 \\
\hline \hline 4 & 92 & Chopped (8) & 0 \\
\hline \hline 5 & 88 & Chopped (12) & 0 \\
\hline \hline 6 & 99 & 0 & 1 \\
\hline \hline 7 & 98 & 0 & 2 \\
\hline \hline 8 & 97 & 0 & 3 \\
\hline \hline 9 & 89 & Woven (8) & 3 \\
\hline 10 & 85 & Woven (12) & 3 \\
\hline \hline 11 & 91 & Chopped (8) & 1 \\
\hline 12 & 89 & Chopped (8) & 3 \\
\hline \hline 13 & 87 & Chopped (12) & 1 \\
\hline 14 & 85 & Chopped (12) & 3 \\
\hline
\end{tabular}

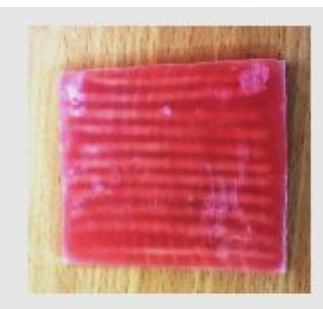

Fig.(2): Specimen of PMMA as denture.

\section{Mechanical Instruments: Flexural Strength Test}

The test was performed by fixing the specimen in the two parallel supports separated by $(50 \mathrm{~mm})$ of Instron tensile testing machine (Instron, 1195). The full scale load was $20 \mathrm{kN}$, the rod was applied on the center of specimen with speed of $5 \mathrm{~mm} / \mathrm{min}$ until fracture occurred. Flexural strength (F.S.) calculated in Pascal (MPa) was determined by applying equation (1) after recording the maximum force from the screen.

$$
\text { F.S. }=3 \mathrm{PL} / 2 \mathrm{bd}^{2} \ldots \ldots \text {...Eq. }
$$

Where,

F.S.: Flexural strength in MPa.

P: Maximum load in (Newton).

L: Span distance ( $\mathrm{mm})$.

b: Width (mm) of the specimen.

d: Thickness $(\mathrm{mm})$ of the specimen.

\section{Results and Discussion}

Flexural strength of a denture base resin is of great concern, and can be represented by the fracture of denture during chewing food due to applied masticator load. The flexural strength represents the highest stress experienced within the material at its moment of rupture . The flexural strength of control group was $78 \mathrm{MPa}$, as shown in Table (2).

\section{a) Samples reinforced with GF}

Fiber-reinforced polymers can be used successfully primarily because of their high specific modulus and specific strength. Table (2) describe the flexural strength results for glass fiber (GF) reinforced denture base resin with ( 8 and $12 \mathrm{wt} . \%$ ). When denture base reinforced with (8wt.\%) woven glass fiber (G2) the flexural strength decreased by $(7.5 \%)$ compared to control group (G1), this reduction may due to probability of voids present in the sample, however in the addition of (12wt. \%) in (G3) the value of flexural strength increased by $(9.7 \%)$, as shown in Fig.(3a). When chopped GF (8wt.\%)(G4) was used, the flexural strength increased by $(32 \%)$ than control group, however it's decrease with more amount of chopped GF in (G5), as shown in Fig.(3b). The increases of flexural strength may due to distribution of stresses on the glass fibers which absorb most stresses before deformation [7]. The more addition of chopped GF (12wt. \%) had adversely effect on the flexural strength due to difficult wetting of fibers.

Table (2)

The flexural strength for denture reinforced with woven and chopped $G F$.

\begin{tabular}{|c||c||c||c|}
\hline $\begin{array}{c}\text { Glass } \\
\text { Fiber } \\
\text { (GF) }\end{array}$ & $\begin{array}{c}\text { flexural } \\
\text { strength } \\
\text { (MPa) } \\
\text { (woven glass } \\
\text { fiber) }\end{array}$ & $\begin{array}{c}\text { Glass } \\
\text { Fiber } \\
\text { (GF) }\end{array}$ & $\begin{array}{c}\text { flexural } \\
\text { strength } \\
\text { (MPa) } \\
\text { (chopped } \\
\text { glass fiber) }\end{array}$ \\
\hline \hline $\begin{array}{c}\text { G1 0wt. } \\
\%\end{array}$ & 78 & $\begin{array}{c}\text { G1 0wt. } \\
\%\end{array}$ & 78 \\
\hline $\begin{array}{c}\text { G2 8wt. } \\
\%\end{array}$ & 73 & $\begin{array}{c}\text { G4 8wt. } \\
\%\end{array}$ & 103 \\
\hline \hline $\begin{array}{c}\text { G3 } \\
12 \mathrm{wt} . \\
\%\end{array}$ & 85.6 & G5 12wt. \\
$\%$ & 42 \\
\hline
\end{tabular}



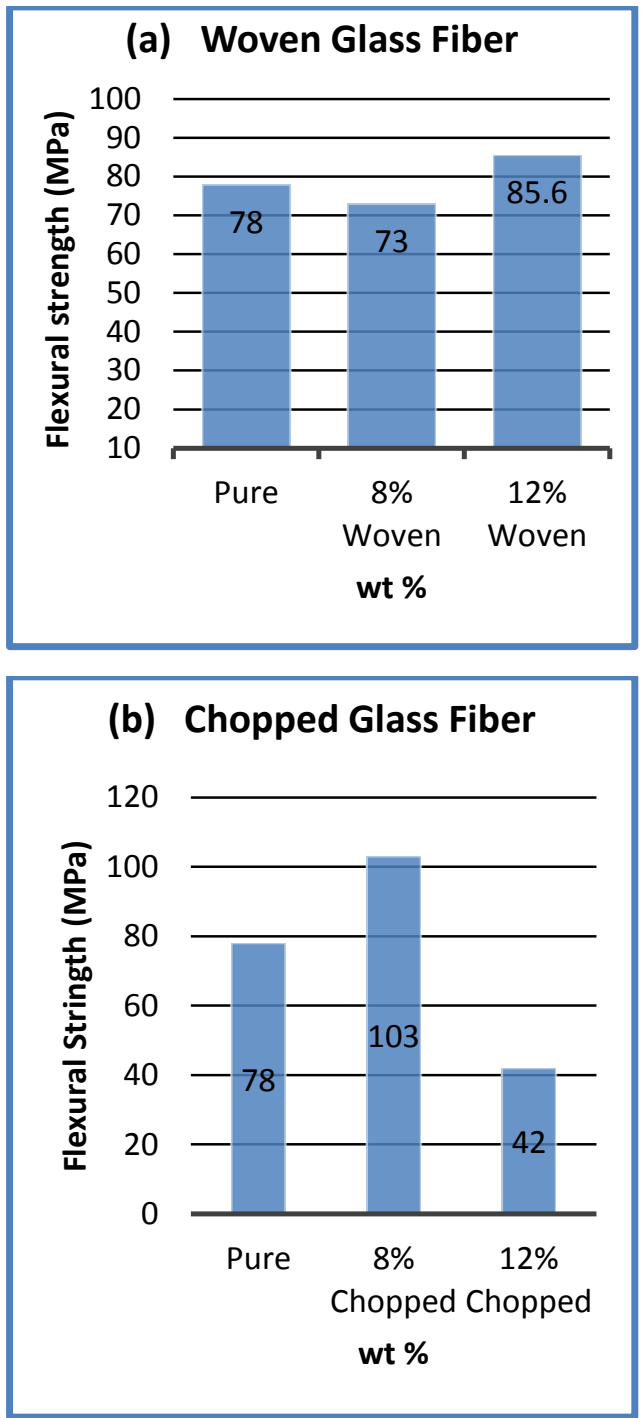

Fig.(3): The flexural strength of denture base acrylic resin PMMA:

(a) Woven GF (b) Chopped GF.

The quantity of glass fibers in cross section of polymer matrix affect flexural strength values. In composites reinforced with (8wt.\%) of glass fiber, the flexural strength of chopped fiber recorded high value than woven fiber. The differences between the two types of reinforcements are probably due to the surface density of fibers, bonding strength of parts, and number of glass fibers per section area of test specimen.

The number of glass fibers is bigger in chopped specimen than in woven specimen [8].

\section{b) Samples reinforced with $\mathrm{ZrO}_{2}$}

Incorporation of zirconia in various dental materials has significant benefit, it was found to be biocompatible, and esthetic appearance. The effect of zirconium oxide nanoparticles
$\left(\mathrm{ZrO}_{2}\right)$ on flexural strength summarized in Table (3) for samples reinforced with $(1,2$, and 3 wt. \%). The results showed that, the flexural strength of PMMA increased with increases amount of $\mathrm{ZrO}_{2}$ powder. The flexural strength of samples (G6, G7, and G8) which reinforced with $\left(1,2\right.$, and 3) wt. $\% \mathrm{ZrO}_{2}$ increased by $(5,12$, and 18$) \%$ as compared to flexural strength of control group (G1), respectively, as shown in Fig. (4). This result is similar to previous study [4]. This increases in flexural strength can be attributed to a good dispersion of the $\mathrm{ZrO}_{2}$ Nano-particles. Segmental motions of the macromolecular chains are restricted and lead to increase strength and rigidity of the resin, so this improve fracture resistance and lead to improve flexural strength [9].

Table (3)

The flexural strength for denture reinforced with $\mathrm{ZrO}_{2}$

\begin{tabular}{|c|c|}
\hline $\begin{array}{c}\text { Zirconium Oxide } \\
\left(\mathbf{Z r O}_{2}\right)\end{array}$ & $\begin{array}{c}\text { Flexural strength } \\
\text { MPa }\end{array}$ \\
\hline \hline G1 0 wt.\% (Control) & 78 \\
\hline G6 1 wt.\% & 82 \\
\hline G7 2 wt.\% & 88 \\
\hline \hline G8 3 wt.\% & 92.2 \\
\hline
\end{tabular}

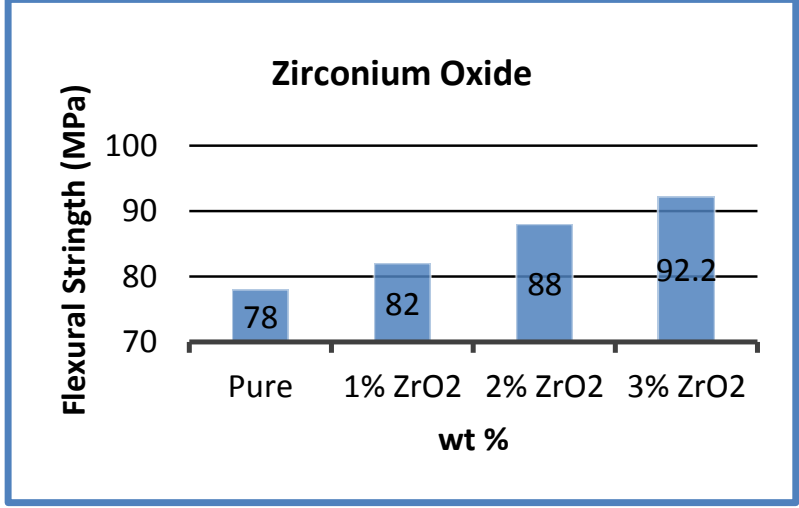

Fig.(4): The flexural strength of denture base acrylic resin PMMA:

Reinforced with $\mathrm{ZrO}_{2}$ Nano-particles

c) Samples reinforced with GF and $\mathrm{ZrO}_{2}$ (hybrid)

Table (4) summarized the results of flexural strength for reinforced PMMA with hybrid woven or chopped GF with $\mathrm{ZrO}_{2}$ Nanopowder in different weight percent. The flexural strength values are higher than control 
group for all samples, as shown in Fig.(5) and (6). The increment in flexural strength values by using woven glass fiber (G9, G10) are $(7.69,21.79) \%$ and in chopped glass fiber (G11, G12, G13, and G14) are $(30,29.48$, 10.25 , and 11.53$) \%$, respectively as compared with control group (G1). This increment is due to a significant positive synergy effect due to fiber and powder hybridization. When the load is applied on the hybrid composite the $\mathrm{ZrO}_{2}$ powder receive the applied load, and after fails then the applied load is transferred to glass fiber, so that the presence of glass fiber in the hybrid composite will causes to improve the flexural strength [10]. The saline coupling agent treatment improves the adhesive characteristics of fiber surface with powder and matrix lead to increase in flexural properties $[6,11]$.

\section{Table (4)}

The flexural strength for denture reinforced with hybrid ( $\mathrm{GF}$ and $\mathrm{ZrO}_{2}$ ).

\begin{tabular}{|c|c|}
\hline Reinforcement & F.S. (MPa) \\
\hline G1 $0 \%$ (control) & 78 \\
\hline $\begin{array}{c}\text { G9 }[(8 \% \text { woven }) \& \\
\left.\left(3 \% \mathrm{ZrO}_{2}\right)\right] \text { wt. } \%\end{array}$ & 84 \\
\hline $\begin{array}{l}\text { G10 }[(12 \% \text { woven }) \& \\
\left.\left(3 \% \mathrm{ZrO}_{2}\right)\right] \text { wt. } \%\end{array}$ & 95 \\
\hline $\begin{array}{c}\text { G11 }[(8 \% \text { chopped }) \& \\
\left.\left(1 \% \mathrm{ZrO}_{2}\right)\right] \text { wt. } \% \\
\end{array}$ & 101.4 \\
\hline $\begin{array}{c}\mathrm{G} 12[(8 \% \text { chopped }) \& \\
\left.\left(3 \% \mathrm{ZrO}_{2}\right)\right] \text { wt. } \%\end{array}$ & 101 \\
\hline $\begin{array}{c}\text { G13 [(12\% chopped }) \& \\
\left.\left(1 \% \mathrm{ZrO}_{2}\right)\right] \text { wt. } \%\end{array}$ & 86 \\
\hline $\begin{array}{l}\text { G14 }[(12 \% \text { chopped }) \& \\
\left.\left(3 \% \mathrm{ZrO}_{2}\right)\right] \text { wt. } \%\end{array}$ & 87 \\
\hline
\end{tabular}

(a) $8 \%$ Woven GF with $3 \%$ ZrO2

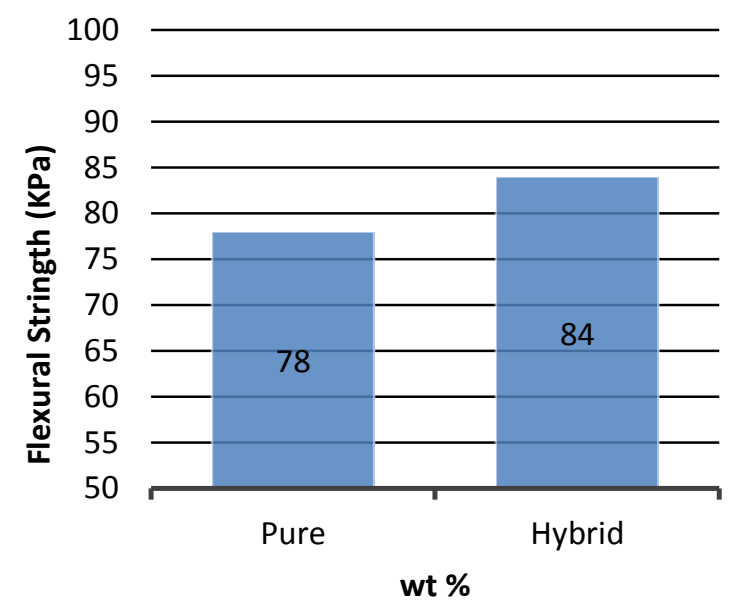

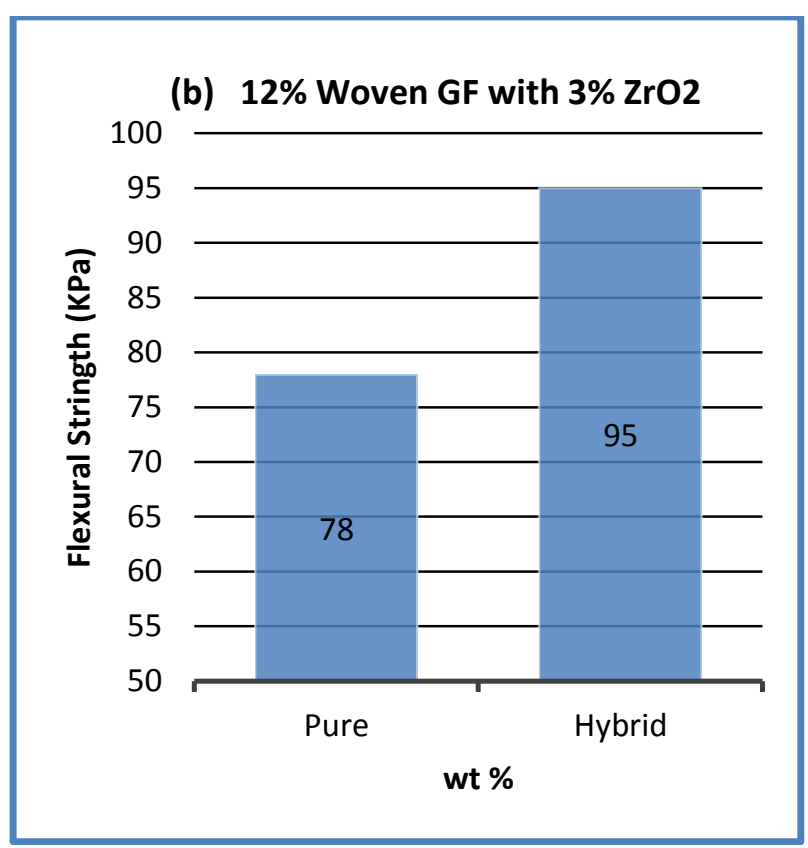

Fig.(5): The flexural strength of woven hybrid denture base acrylic resin.

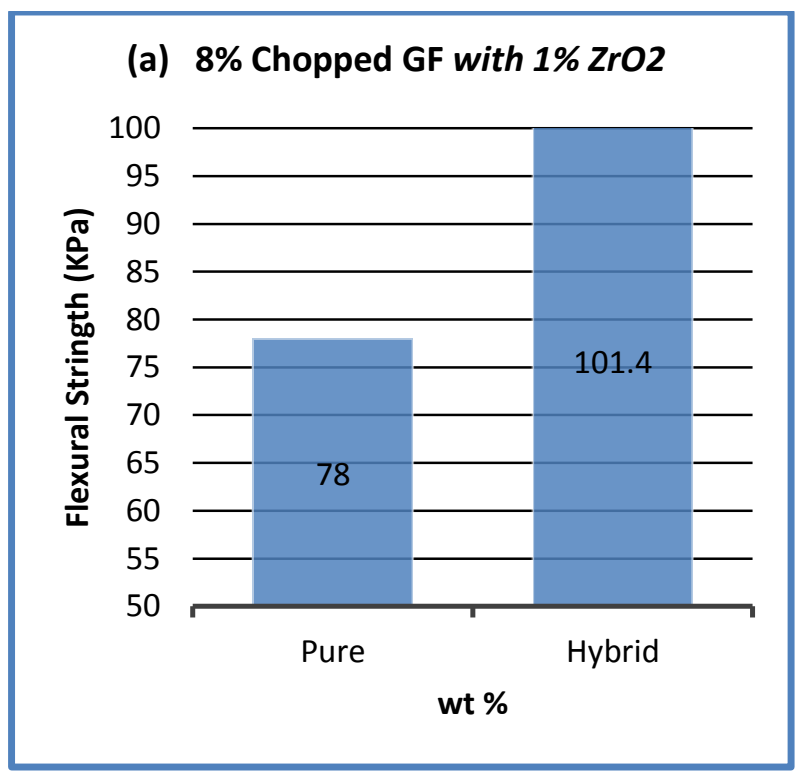

(b) $8 \%$ Chopped GF with $3 \%$ ZrO2

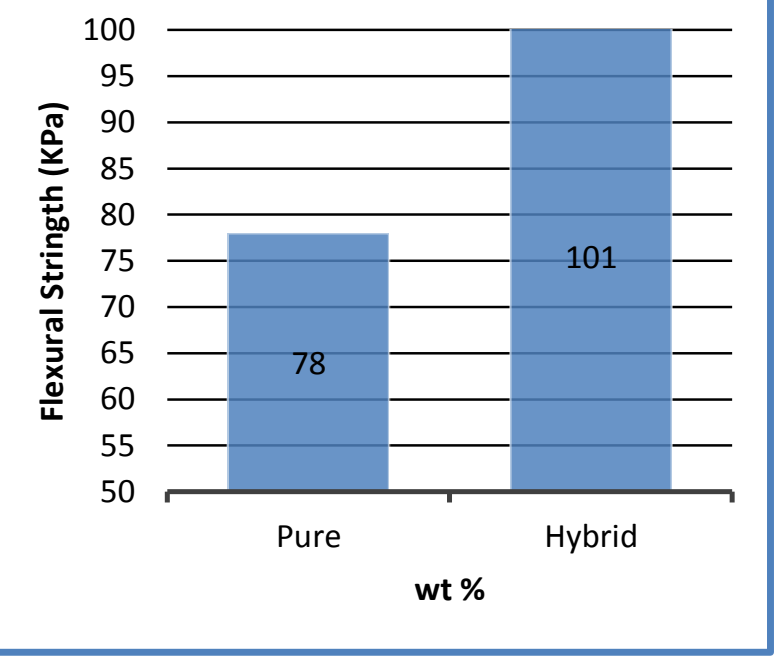



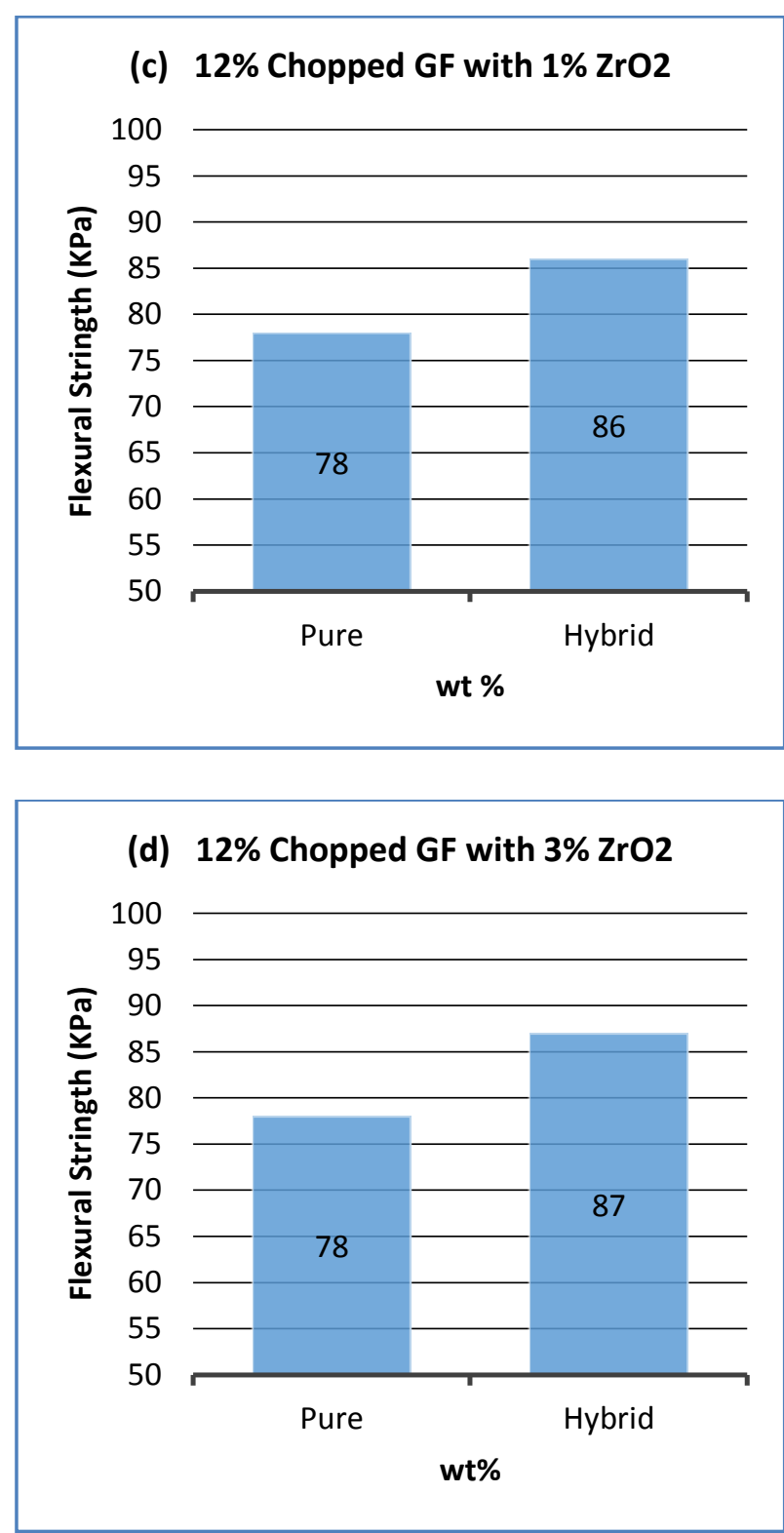

Fig.(6): The flexural strength of chopped hybrid denture base acrylic resin.

\section{Conclusion}

1. The form of glass fiber with the same weight present affects the properties values.

2. Reinforcing PMMA with woven glass fiber and zirconium oxide increases flexural strength, while chopped glass fiber decreases flexural strength. The using of two materials together as a hybrid composite recorded very high raises of flexural strength values.

3. So, it's possible to syntheses a denture base resin with good aesthetic and high mechanical properties.

\section{References}

[1] Robert L. Engelmeier DMD, MS, "The history and development of posterior denture teeth-introduction, part II: Artificial tooth development in America through the nineteenth century", university of Texas-Houston, dental branch, 12(4), 2003.

[2] Rama Krishna Alla, Suresh Sajjan, Venkata Ramaraju Alluri, Kishore Ginjupalli, and Nagaraj Upadhya, "Influence of Fiber Reinforcement on the Properties of Denture Base Resins", Department of Dental Materials, Vishnu Dental College, Bhimavaram, India,4, 9197, 2012.

[3] M. Vojdani, and AAR. Khaledi, "Transverse Strength of Reinforced Denture Base Resin with Metal Wire and E-Glass Fibers", Department of Prosthodontics, Faculty of Dentistry, Shiraz University of Medical Sciences, Shiraz, Iran, 3(4), 2006.

[4] Neveen M. Ayad, Manal F. Badawi1, and Abdou A. Fatah, "Effect of Reinforcement of High-Impact Acrylic Resin with Zirconia on Some Physical and Mechanical Properties", Department of Dental Biomaterials, Faculty of Dentistry, Mansoura University, Mansoura, Egypt, 4, N. 3, 145-151, 2008.

[5] Russel R. Ghanim, "Denture Base Modification by Reinforcement of Carbon Fiber/ Hydroxyapatite and Study its Properties", Department of Applied science, M.Sc. Thesis, the University of Technology, Iraq, 2014.

[6] Ibrahim M Hamouda, Mohammed M Beyari, "Addition of Glass Fibers and Titanium Dioxide Nanoparticles to the Acrylic Resin Denture Base Material: Comparative Study with the Conventional and High Impact Types", Department of Dental Biomaterials, Faculty of Dentistry, Mansoura University, Egypt, 13(1), 2014.

[7] IH Tacir, JD Kama, M Zortuk, and S Eskimez, "Flexural properties of glass fibre reinforced acrylic resin polymers", Department of Prosthodontics, Faculty of Dentistry, Dicle University, Diyarbakir, Turkey, 51,(1), 52-56, 2006. 
[8] Luciana Goguta, Liviu Marsavina, Dorin Bratu, Florin Topala, "Impact Strength of Acrylic Heat Curing Denture Base Resin Reinforced with E-Glass Fibers", Department of Prosthodontics, Faculty of Dental Medicine, Victor Babes University of Medicine and Pharmacy, NO.1, 2006.

[9] Hussein Karim Hameed, Hanan Abdul Rahman, "The effect of addition nano particle $\mathrm{ZrO}_{2}$ on some properties of autoclave processed heat cure acrylic denture base material", Department of Prosthodontics, College of Dentistry, University of Baghdad,27(1), 2015.

[10] V. NAGA PRASAD NAIDU, M.ASHOK KUMAR, G.RAMACHANDRA REDDY3, P.NOORUNNISA KHANAM3, M.MOHAN REDDY, K.V.P.CHAKRADHAR, "Tensile $\&$ flexural properties of sisal/glass fibre reinforced hybrid composites", Department of Mechanical Engineering, Moula Ali College of Engineering \& Technology, Gotkur, Kuderu-Mdl, Anantapur 515711, India, 1(1), 19-22, 2011.

[11] Yanjun Xiea, b, Callum A. S. Hillb, Zefang Xiaoa, Holger Militza, Carsten Maia, "Silane coupling agents used for natural fiber/polymer composites", Wood Biology and Wood Products, BurckhardtInstitute, Georg August University of Göttingen, Büsgenweg 4, D37077 Göttingen, Germany, 41, 806-819, 2014. 